\title{
Hubungan Persepsi Label Halal MUI Terhadap Minat Beli Produk Makanan Pada Mahasiswa Fakultas Ilmu Kesehatan Universitas Muhammadiyah Surakarta
}

\author{
Kurnia Fitra Nanda ${ }^{1,2}$, Retty Ikawati ${ }^{3}$ \\ ${ }^{1)}$ Prodi Ilmu Gizi, Fakultas Ilmu Kesehatan Universitas Muhammadiyah Surakarta, \\ ${ }^{2}$ Puskesmas Suka Datang Dinas Kesehatan Kabupaten Lebong Provinsi Bengkulu \\ 3)Prodi Bisnis Jasa Makanan Universitas Ahmad Dahlan \\ kurnia.fitran@gmail.com, rettyikawati@gmail.com
}

\begin{abstract}
Islam regulates about halal and haram in the food aspect. Food is a prime needed that support physical activity. Knowing about halal food is vital in public society, mainly for the Muslim. Generally, Muslim consumer will have a positive perspective toward food product which uses halal approach. Consumer's perception in choosing halal label on food gives a positive effect on consumer's decision in buying interest. Indonesia, with a Muslim majority population, surely will bring a significant impact on the growing culture in Indonesia, primarily in food culture. In Indonesia, halal food is already regulated by Majelis Ulama Indonesia (MUI) which is technically handled by Lembaga Pengkajian Pangan Obatobatan (LPPOM) by releasing halal certificate and halal label. Halal label is a sign of halalness of a product. The research aims to know the correlation of MUI halal label perception with buying interest on food product on faculty of health science in Universitas Muhammadiyah Surakarta. The study is observational research with cross-sectional approach. The total subject of this research was 62, which selected with the proportionate stratified random sampling method. The data of halal label perception and buying interest gotten by using the google form questionnaire. The scale uses a Likert level. Data analysis uses the Spearman rank test. The result of the research shows the perception of MUI halal label perception respondents includes to the low category $(54,8 \%)$. The buying interest in food product mostly consists of the high class $(58,1 \%)$. The result of the Spearman rank test for MUI halal perception certification with buying interest on food product $\mathrm{p}$-value $=0,000$. There is a relation between MUI halal label perception with buying interest in the food product.
\end{abstract}

Keywords: Health faculty, percetion, halal label, buying interest, student.

\section{ABSTRAK}

Islam mengatur banyak mengenai halal dan haram dalam bidang makanan. Makanan adalah kebutuhan primer yang menunjang aktifitas fisik. Pengetahuan mengenai makanan halal sangat penting bagi masyarakat umum, terutama umat Islam. Secara umum, konsumen Muslim akan memiliki persepsi yang positif terhadap produk makanan yang menggunakan pendekatan halal. Persepsi konsumen dalam menentukan label halal pada makanan berpengaruh positif terhadap keputusan konsumen dalam menentukan minat beli. Indonesia dengan populasi penduduk mayoritas Muslim, tentu akan membawa pengaruh yang besar bagi budaya yang berkembang di Indonesia, terutama dalam budaya konsumsi pangan. Di Indonesia makanan halal sudah diatur oleh Majelis Ulama Indonesia (MUI) yang secara teknis ditangani oleh Lembaga Pengkajian Pangan Obat-obatan (LPPOM) dengan mengeluarkan sertifikat halal dan label halal. Label Halal adalah tanda kehalalan suatu produk. Penelitian ini bertujuan untuk mengetahui hubungan persepsi label halal MUI dengan minat beli produk makanan pada mahasiswa Fakultas Ilmu Kesehatan Universitas Muhammadiyah Surakarta. Penelitian ini merupakan penelitian observasional dengan pendekatan cross sectional. Jumlah subjek penelitian sebanyak 62 dipilih dengan metode propotionate stratified random sampling. Data persepsi sertifikasi halal dan data minat beli diperoleh dengan menggunakan kuesioner di google form. Skala menggunakan skala Likert. Analisis data dengan uji Rank Spearman. Hasil penelitian menunjukkan persepsi label halal MUI responden termasuk dalam kategori rendah (54,8\%). Minat beli produk makanan sebagian besar termasuk dalam kategori tinggi $(58,1 \%)$. Hasil uji Rank Spearman untuk persepsi label halal MUI dengan minat beli produk makanan nilai $\mathrm{p}=0,000$. Ada hubungan persepsi label halal MUI dengan minat beli produk makanan.

Kata Kunci: Fakultas Ilmu Kesehatan, persepsi, label halal, minat beli, mahasiswa 


\section{PENDAHULUAN}

Islam telah mengatur banyak hal mengenai halal dan haram di bidang makanan. Halal adalah sebuah konsep aturan prinsip agama Islam, yang digunakan untuk menyatakan bahwa sesuatu hal diijinkan atau dilarang untuk dikonsumsi oleh Muslim dengan dasar dari AlQur'an, Hadist, atau Ijtihad (kesepakatan ulama) (Ahmad dkk, 2013). Dalam ajaran Islam, seorang muslim diajarkan untuk mengonsumsi makanan yang halal. Muslim dilarang mengonsumsi daging babi, alkohol, darah, daging mati dan daging yang tidak disembelih menurut hukum Islam (QS: Al-Baqarah : 173).

Makanan adalah kebutuhan primer yang menunjang aktifitas fisik manusia. Dalam bidang gizi, makanan adalah bahan selain obat, mengandung zat-zat gizi dan atau unsurunsur/ikatan kimia yang dapat diubah menjadi zat gizi oleh tubuh, dan berguna bila dimasukkan ke dalam tubuh (Almatsier, 2001). Pengetahuan mengenai makanan halal sangat penting bagi masyarakat umum, terutama umat Islam, karena perilaku konsumen manusia sangat tergantung dari apa yang dimakannya (Sumarwan, 2011). Secara umum konsumen Muslim akan memiliki persepsi yang positif terhadap produk-produk makanan yang menggunakan pendekatan halal (Shafie \& Othman, 2006). Dengan demikian seyogyanya pengetahuan tersebut menjadi persepsi yang kuat di benak penduduk Muslim di Indonesia. Bonne \& Verbeke (2006) dalam penelitiannya mengemukakan bahwa agama bisa mempengaruhi sikap dan perilaku konsumen secara umum, khususnya dalam keputusan pembelian makanan dan kebiasaan makan.

Data statistik Sensus Penduduk Indonesia pada tahun 2010 hingga tahun 2013 menunjukkan bahwa penduduk yang beragama Islam di Indonesia mencapai 207.176.162 juta jiwa atau $87,21 \%$ dari total populasi di Indonesia yang berjumlah 237.641.326 juta jiwa (Badan Pusat Statistik Pusat Jakarta, 2010). Indonesia dengan populasi penduduk mayoritas Muslim, tentu akan membawa pengaruh yang besar bagi budaya yang berkembang di Indonesia, terutama dalam budaya konsumsi pangan. Di Indonesia makanan halal yang beredar di masyarakat sudah diatur oleh Majelis Ulama Indonesia (MUI) yang secara teknis ditangani oleh Lembaga Pengkajian Pangan Obat-obatan, dan Kosmetika (LPPOM) dengan mengeluarkan sertifikat hala dan label halal. Sertifikasi halal dapat didefinisikan sebagai pengakuan kehalalan suatu produk yang dikeluarkan oleh Badan Penyelenggara Jaminan Produk Halal (BPJH) berdasarkan fatwa yang tertulis yang dikeluarkan oleh MUI dan label halal adalah tanda kehalalan suatu produk (UU RI, 2014).

Hasil survey pendahuluan yang telah dilakukan di Fakultas Ilmu Kesehatan mendapatkan sebanyak $80 \%$ mahasiswa memiliki minat beli yang tinggi pada produk makanan tanpa mensyaratkan label halal MUI. Berdasarkan uraian tersebut maka peneliti tertarik meneliti tentang hubungan persepsi label halal MUI terhadap minat beli produk makanan pada mahasiswa Fakultas Ilmu Kesehatan Universitas Muhammadiyah Surakarta.

\section{METODE}

Jenis penelitian ini bersifat observasional dengan penelitian cross-sectional. Waktu penelitian ini dilaksanakan pada bulan Januari 2018. Lokasi penelitian dilakukan di FIK Universitas Muhammadiyah Surakarta. Populasi dari penelitian ini adalah seluruh Mahasiswa FIK yang berjumlah 631 orang. Besar sampel yang dibutuhkan dalam penelitian ini berdasarkan perhitungan adalah 62 orang.

Pengambilan sampel dilakukan secara Propotionate Stratified Random Sampling, yaitu mengambil sampel dari tiap kelas jurusan secara seimbang sesuai dengan banyaknya subyek dalam masing-masing kelas.

Data penelitian ini terdiri dari data primer dan data sekunder. Data primer meliputi data identitas diri, data persepsi label halal, dan data minat beli. Data identitas diri menggunakan kuesioner kesediaan sebagai responden sedangkan data persepsi label halal dan data minat beli dengan cara meminta responden untuk mengisi kuesioner yang ada di google form. Skala 
pengukuran instrumen pada penelitian ini menggunakan skala Likert. Kategori persepsi label halal dikatakan rendah jika $<33,2$ dan dikatakan tinggi jika $\geq 33,2$. Kategori minat beli dikatakan rendah jika $<13,3$ dan dikatakan tinggi jika $\geq 13,3$. Data sekunder terdiri dari gambaran FIK Universitas Muhammadiyah Surakarta dan jumlah mahasiswa yang diperoleh dengan cara dokumentasi dan observasi, yaitu dengan mencatat dan mengamati keadaan lingkungan di FIK Universitas Muhammadiyah Surakarta.

Analisis data menggunakan program SPSS for windows versi 16.0. Uji kenormalan data menggunakan Kolmogorov Smirnov. Hubungan persepsi label halal terhadap minat beli menggunakan uji Rank Spearman. Signifikansi nilai $\mathrm{p}$ adalah jika nilai $\mathrm{p}<0,05$.

\section{HASIL DAN PEMBAHASAN}

\subsection{Gambaran Umum Kebiasaan Makan Mahasiswa Fakultas Ilmu Kesehatan}

Mahasiswa Fakultas Ilmu Kesehatan (FIK) umumnya memiliki kebiasaan pola makan yang sama, yaitu sering mengkonsumsi makanan cepat saji. Hal ini dipilih mahasiswa karena waktu kuliah yang padat belum ditambah lagi jadwal praktik yang mengharuskan mahasiswa harus mendapatkan makanan secara cepat dan mudah kenyang.

Berdasarkan survey yang telah dilakukan pada mahasiswa dan kantin yang tersedia di kampus, mahasiswa FIK rata-rata mengkonsumsi makanan yang dijual di kantin. Makanan yang dijual dikantin adalah makanan siap santap yang merupakan makanan tinggi karbohidrat, lemak dan kolesterol seperti nugget dan sosis. Mahasiswa juga mengkonsumsi produk makanan seperti roti, coklat dan makanan ringan lainnya. Alasan responden memilih makanan yang dikonsumsi karena lebih praktis dikonsumsi. Responden jarang sekali melihat bahwa produk itu bersertifikasi halal atau tidak karena memilih produk makanan dari apa yang sudah disediakan oleh pedagang saja.

\subsection{Analisis Univariat}

\subsubsection{Distribusi Responden menurut Program Studi}

Responden dalam penelitian ini adalah Mahasiswa FIK Universitas Muhammadiyah Surakarta dengan distribusi karakteristik program studi seperti pada tabel 1.

Tabel 1. Distribusi Responden menurut Program Studi

\begin{tabular}{ccc}
\hline Program Studi & Jumlah $(\mathrm{n})$ & Persentase $(\%)$ \\
\hline S1 Gizi & 15 & 24,1 \\
S1 Keperawatan & 13 & 21 \\
S1 Fisioterapi & 12 & 19,4 \\
S1 Kesehatan Masyarakat & 12 & 19,4 \\
D3 Fisioterapi & 10 & 16,1 \\
\hline Total & 62 & 100 \\
\hline
\end{tabular}

Tabel 1 menunjukan bahwa responden dengan program studi S1 Gizi dan S1 Keperawatan sebesar 24,1\% dan 21\%, S1 Fisioterapi dan S1 Kesehatan Masyarakat sebesar 19,4\%, dan program studi D3 Fisioterapi sebesar 16,1\%. Mahasiswa FIK Universitas Muhammadiyah Surakarta telah dibekali materi keislaman dan kehalalan pangan. Mahasiswa adalah konsumen yang sering mengkonsumsi produk makanan dalam kemasan.

\subsubsection{Distribusi Responden menurut Jenis Kelamin}

Responden dalam penelitian ini adalah Mahasiswa FIK Universitas Muhammadiyah Surakarta dengan distribusi karakteristik jenis kelamin seperti pada tabel 2.

Tabel 2. Distribusi Responden menurut Jenis Kelamin

\begin{tabular}{ccc}
\hline Jenis Kelamin & Jumlah $(\mathrm{n})$ & Persentase $(\%)$ \\
\hline Laki-laki & 14 & 22,6 \\
Perempuan & 48 & 77,4 \\
\hline Total & 62 & 100
\end{tabular}

Tabel 2 menunjukkan bahwa mayoritas responden berjenis kelamin perempuan yaitu sebesar $77,4 \%$. 


\subsubsection{Distribusi Responden menurut Usia}

Mahasiswa adalah seseorang yang berusia 19 sampai 28 tahun, dimana pada usia ini menjadi dasar masa perpindahan dari masa remaja ke masa dewasa (Siswoyo, 2007). Responden dalam penelitian ini adalah Mahasiswa FIK Universitas Muhammadiyah Surakarta dengan distribusi karakteristik usia seperti pada tabel 3.

Tabel 3. Distribusi Responden menurut Usia

\begin{tabular}{ccc}
\hline Usia & Jumlah $(\mathrm{n})$ & Persentase $(\%)$ \\
\hline 19 & 45 & 72,6 \\
20 & 16 & 25,8 \\
21 & 1 & 1,6 \\
\hline Total & 62 & 100
\end{tabular}

Tabel 3 menunjukkan bahwa mayoritas responden berusia 19 tahun sebesar $72,6 \%$.

\subsubsection{Distribusi persepsi label halal MUI}

Agama merupakan keyakinan dan nilai-nilai dalam menginterpretasi kehidupan yang diekspresikan menjadi suatu kebiasaan sehingga menjadi elemen kunci yang akan mempengaruhi perilaku dan keputusan membeli pada diri seseorang (Soesilowati, 2010). Responden dalam penelitian ini adalah Mahasiswa FIK Universitas Muhammadiyah Surakarta dengan distribusi karakteristik agama seperti pada tabel 4 .

Tabel 4. Distribusi Responden menurut agama

\begin{tabular}{ccc}
\hline Agama & Jumlah $(\mathrm{n})$ & Persentase $(\%)$ \\
\hline Islam & 62 & 100 \\
\hline Total & 62 & 100 \\
\hline
\end{tabular}

Konsumsi makanan seseorang dipengaruhi banyak faktor. Faktor-faktor yang mempengaruhi konsumsi makanan antara lain yaitu agama, ras, pengetahuan, persepsi, dan lainlain. Agama memiliki perintah dan larangan untuk mengonsumsi makanan-makanan tertentu. Agama Hindu dan Budha adalah kelompok vegetarian, bangsa Yahudi memiliki aturan terhadap makanan yang disebut dengan aturan Kosher. Agama Islam memiliki aturan makanan halal dan makanan haram (Riaz \& Chaudry, 2004). Umat Islam hanya dibolehkan mengkonsumsi makanan yang halal saja, sedangkan untuk makanan yang haram harus ditinggalkan. Responden dalam penilitian ini $100 \%$ menganut agama Islam.

Persepsi label halal MUI dalam penelitian ini diambil dengan menggunakan kuesioner. Data diambil dengan cara responden mengisi kuesioner sendiri yang sebelumnya dijelaskan dahulu oleh peneliti dengan 14 butir pertanyaan dengan skala likert 1 sampai dengan 5 . Distribusi statistik deskriptif menurut persepsi label halal MUI dapat dilihat pada tabel 5.

Tabel 5. Distribusi statistik deskriptif persepsi label halal MUI

\begin{tabular}{cc}
\hline Statistik Deskriptif & Persepsi label Halal \\
\hline Rata-rata & 33,22 \\
Standar deviasi & 5,48 \\
Nilai Maksimal & 43,50 \\
Nilai Minimal & 19,00 \\
\hline
\end{tabular}

Responden dalam penelitian ini memiliki nilai rata-rata skor persepsi label halal MUI sebesar 33,22, standar deviasi 5,48, nilai maksimal 43,50 yang tergolong dalam kategori persepsi label halal tinggi dan nilai minimal 19,00 yang tergolong dalam kategori persepsi label halal rendah. Kategori persepsi label halal dikatakan tinggi jika skor persepsi $\geq 33,22$ dan rendah jika skor persepsi $<33,22$. Distribusi responden menurut persepsi label halal MUI dapat dilihat pada tabel 6 .

Tabel 6. Distribusi Responden menurut persepsi label halal MUI 


\begin{tabular}{ccc}
\hline Kategori & Jumlah $(\mathrm{n})$ & Persentase $(\%)$ \\
\hline Rendah & 34 & 54,8 \\
Tinggi & 28 & 45,2 \\
\hline Total & 62 & 100 \\
\hline
\end{tabular}

Tabel 6 menunjukkan bahwa responden yang memiliki persepsi label halal MUI dalam kategori rendah $<33,22$ sebesar $54,8 \%$ dan persepsi label halal MUI tinggi $\geq 33,22$ sebesar 45,2\%. Hal ini sejalan dengan peneiltian Wahyuni (2015) menunjukkan bahwa persentase persepsi sertifikasi halal konsumen muslim yang menganggap penting lebih rendah dari pada persentase konsumen yang menganggap tidak penting. Penelitian Waskito (2015) juga menunjukkan bahwa persepsi sertifikasi halal rendah 16,7\% dibandingkan sedang 62,7\% dan tinggi 20,5\%. Konsumen akan memandang suatu produk berdasarkan apa yang ada didalam persepsinya. Konsumen akan memandang produk makanan halal, jika terdapat sertifikasi halal pada produk makanan. Dalam penelitian ini, responden yang sudah belajar tentang sertifikasi halal adalah jurusan Gizi, sedangkan tiga jurusan lain belum belajar tentang sertifikasi halal. Hal inilah yang menjadikan persepsi label halal rendah.

Persepsi adalah kesan yang diperoleh oleh seseorang melalui panca indera yang selanjutnya di analisa, diinterpretasi dan di evaluasi, sehingga individu tersebut memperoleh suatu makna (Robbins, 2016). Persepsi adalah proses mengorganisasi dan menginterpretasikan informasi sensoris agar informasi menjadi bermakna (King, 2016). Dalam penelitian ini, persepsi sertifikasi halal MUI dapat diartikan sebagai kesan yang telah di analisa, diinterpretasi, dan di evaluasi oleh seseorang sehingga menghasilkan suatu makna bahwa apapun yang berlabel halal telah terjamin kehalalannya oleh MUI.

\subsubsection{Distribusi minat beli produk makanan}

Minat beli dalam penelitian ini penelitian ini diambil dengan menggunakan kuesioner. Data diambil dengan cara responden mengisi kuesioner sendiri yang sebelumnya dijelaskan dahulu oleh peneliti dengan 6 butir pertanyaan dengan skala likert 1 sampai dengan 5 . Distribusi statistik deskriptif menurut minat beli produk makanan dapat dilihat pada tabel 7.

Tabel 7. Distribusi statistik deskriptif minat beli produk makanan

\begin{tabular}{cc}
\hline Statistik Deskriptif & Minat beli produk makanan \\
\hline Rata-rata & 13,30 \\
Standar deviasi & 3,46 \\
Nilai Maksimal & 18,50 \\
Nilai Minimal & 5,70 \\
\hline
\end{tabular}

Responden dalam penelitian ini memiliki nilai rata-rata minat beli produk makanan sebesar 13,30, standar deviasi 3,46, nilai maksimal 18,50 yang tergolong dalam kategori tinggi dan nilai minimal 5,70 yang tergolong dalam kategori rendah. Kategori minat beli produk makanan dikatakan tinggi jika skor $\geq 13,30$ dan rendah jika skor minat beli produk makanan $<13,30$. Distribusi responden menurut minat beli produk makanan dapat dilihat pada tabel 8 .

Tabel 8. Distribusi Responden menurut minat beli produk makanan 


\begin{tabular}{ccc}
\hline Kategori & Jumlah $(\mathrm{n})$ & Persentase $(\%)$ \\
\hline Rendah & 26 & 41,9 \\
Tinggi & 36 & 58,1 \\
\hline Total & 62 & 100 \\
\hline
\end{tabular}

Tabel 8 menunjukkan bahwa responden yang memiliki minat beli produk makanan rendah $<13,30$ sebesar $41,9 \%$ dan minat beli produk makanan tinggi $\geq 13,30$ sebesar $58,1 \%$. Konsumen melakukan berbagai pertimbangan sebelum memutuskan untuk membeli produk makanan. Penelitian Nugraha dkk. (2017) menyebutkan bahwa minat beli konsumen tidak selalu didasari dengan pemikiran konsumen terhadap produk, melainkan berdasarkan pada keingintahuan konsumen terhadap produk makanan.

Minat beli adalah pernyataan mental dari diri konsumen yang mereflesksikan rencana pembelian sejumlah produk tertentu (Ali, 2011). Minat beli juga didefinisikan sebagai perilaku yang muncul dari respon terhadap objek yang menunjukkan keinginan pelanggan untuk membeli (Kotler \& Amstrong, 2003). Dalam penelitian ini, minat beli dapat diartikan sebagai kecenderungan konsumen untuk membeli sesuatu atau mengambil tindakan yang berhubungan dengan membeli dan diukur dengan tingkat kemungkinan konsumen melakukan pembelian suatu produk.

\subsection{Analisis Bivariat}

\subsubsection{Hubungan persepsi label halal MUI dengan minat beli produk makanan}

Analisis uji hubungan persepsi label halal MUI dengan minat beli produk makanan dapat dilihat pada tabel 9.

Tabel 9

Analisis uji hubungan persepsi label halal MUI dengan minat beli produk makanan

\begin{tabular}{clllll}
\hline Variabel & Rata-rata & Minimal & Maksimal & St. Deviasi & $\mathrm{p}$ \\
\hline Persepsi label halal MUI & 33,22 & 19,00 & 43,50 & 5,48 & 0,000 \\
Minat beli produk makanan & 13,30 & 5,70 & 18,50 & 3,46 & \\
\hline
\end{tabular}

*) Uji Rank Spearman

Tabel 9 menunjukkan bahwa hasil uji statistik dengan Rank Spearman didapatkan nilai $\mathrm{p}=0,000(\mathrm{p}<0,05)$ maka $\mathrm{H0}$ ditolak sehingga dapat disimpulkan bahwa ada hubungan persepsi label halal MUI dengan minat beli produk makanan pada mahasiswa FIK Universitas Muhammadiyah Surakarta. Distribusi persepsi label halal MUI dengan minat beli produk makanan dapat dilihat pada tabel 10.

Tabel 10

Distribusi persepsi label halal MUI dengan minat beli produk makanan

\begin{tabular}{cccccccc}
\hline Persepsi & \multicolumn{3}{c}{ Minat beli produk makanan } & & \multicolumn{2}{c}{ Total } \\
\cline { 2 - 5 } label halal MUI & \multicolumn{3}{c}{ Rendah } & \multicolumn{2}{c}{ Tinggi } & & n \\
\cline { 2 - 6 } & $\mathbf{n}$ & $\mathbf{\%}$ & $\mathbf{n}$ & $\mathbf{\%}$ & & $\mathbf{\%}$ \\
\hline Rendah & 21 & 61,8 & 13 & 38,2 & & 34 & 100 \\
Tinggi & 5 & 17,9 & 23 & 82,1 & 28 & 100 \\
\hline
\end{tabular}

Tabel 10 menunjukkan bahwa responden yang memiliki persepsi label halal MUI rendah memiliki minat beli produk makanan rendah $(61,8 \%)$, minat beli produk makanan tinggi sebesar $38,2 \%$. Sedangkan responden yang memiliki persepsi label halal MUI tinggi memiliki minat beli produk makanan rendah $(17,9 \%)$, minat beli produk makanan tinggi sebesar $82,1 \%$. 
Tabel 10 menunjukkan bahwa ada kecendrungan pada responden dengan persepsi label halal tinggi memiliki minat beli produk makanan tinggi dengan nilai $\mathrm{p}=0,000(\mathrm{p}<0,05)$ yaitu ada hubungan persepsi label halal terhadap minat beli produk makanan. Hal ini sejalan dengan penelitian Kurniawan (2017) yang menyebutkan bahwa terdapat hubungan antara persepsi konsumen tentang kehalalan produk Samyang terhadap minat beli produk Samyang, dan menjadi indikasi bahwa semakin baik persepsi konsumen maka minat belinya akan semakin tinggi. Penelitian Cahyati (2016) menunjukkan bahwa ada pengaruh pencantuman label halal terhadap minat beli terhadap luwak white coffee pada mahasiswa Fakultas Ekonomi Universitas 17 Agustus 1945 Samarinda.

Penelitian lain dari Rambe \& Afifuddin (2012) menjelaskan bahwa dengan adanya label halal yang tercantum pada kemasan produk, maka secara langsung akan memberikan pengaruh bagi konsumen khususnya masyarakat muslim untuk menggunakan produk tersebut, munculnya rasa aman dan nyaman dalam mengkonsumsi prodok tersebut akan meningkatkan kepercayaan. Berdasarkan hal ini dapat disimpulkan fungsi dari label halal adalah sebagai tanda pemberi kepastian akan status kehalalan suatu produk makanan, mulai dari segi kandungan bahan pangan, proses pengolahan, dan juga tempat produksinya yang memberi kenyamanan bagi konsumen untuk mengkonsumsi suatu produk.

Konsumen akan memandang suatu produk berdasarkan apa yang ada didalam persepsinya. Persepsi sertifikasi halal MUI yang ada di benak konsumen akan menimbulkan kepercayaan konsumen pada keamanan halal. Persepsi tersebut akan ditampilkan melalui sikap dan perilaku konsumen dalam menentukan minat beli pada produk makanan. Teori Pemrosesan Informasi dari William McGuire menjelaskan bahwa reaksi konsumen terhadap stimulus bergantung pada bagaimana stimulus bersangkutan diproses, dan itu akan sangat membentuk sikap dan perilaku. Reaksi dari seseorang terhadap informasi terkait halal atau tidaknya suatu produk akan bergantung pada bagaimana informasi tersebut diproses dan selanjutnya pemroresan informasi tersebut dapat membentuk sikap dan perilaku terhadap produk. Sikap dan perilaku salah satu dari faktor minat beli seseorang. Minat beli seseorang juga dipengaruhi oleh sertifikasi halal. Hal ini sejalan dengan penelitian Aziz \& Chok (2013) menemukan bahwa sertifikasi halal berpengaruh positif terhadap minat pembelian produk.

Minat beli juga dipengaruhi oleh beberapa faktor seperti pengetahuan pelanggan, kemasan produk, dan dukungan selebriti (Younus dkk., 2015). Penelitian dari Rao \& Monroe (1988) menunjukkan bahwa pengetahuan tetang produk adalah faktor utama dalam minat beli produk. Fiore (2008) juga menjelaskan faktor yang sangat penting adalah kemasan produk dan dibuktikan oleh penelitian Fung dkk. (2004) yang mengungkapkan bahwa perasaan konsumen melekat dengan desain dan kemasan produk.

\section{KESIMPULAN}

Persepsi label halal MUI responden termasuk dalam kategori rendah sebesar 54,8\%, minat beli responden termasuk dalam kategori tinggi sebesar $58,1 \%$. Ada hubungan yang signifikan antara persepsi label halal MUI dengan minat beli produk makanan pada mahasiswa FIK Universitas Muhammadiyah Surakarta $(\mathrm{p}<0,05)$. Disarankan bagi Universitas Muhammadiya Surakarta mampu memberikan edukasi mengenai pentingnya label halal MUI kepada seluruh mahasiswa yaitu dengan diadakannya kuliah umum dengan melibatkan pihak dari MUI sehingga mahasiswa mulai melihat dan mempertimbangkan dalam memilih makanan yang sudah ada label halalnya. Sedangkan untuk peneliti selanjutnya perlu adanya penelitian yang lebih mendalam berkaitan dengan faktor lain yang akan mempengaruhi label halal MUI dan minat beli, perlu juga adanya penambahan isi kuesioner yang lebih mendalam agar hasil penelitian lebih menggambarkan persepsi label halal MUI dan minat beli produk makanan. 


\section{DAFTAR PUSTAKA}

Ahmad, M., Kadir, S. A., \& Salehuddin, N. A. (2013). Perceptions and Behavior's of Muslims and Non-Muslims towards Halal Products. Journal of Social and Development Sciences, 4(6), 249-257.

Ali, H. (2011). Marketing dan Kasus-kasus Pilihan. In CAPS (Center For Academic Publishing Service) (p. 89). CAPS.

Al-Qur'an. Al-Baqarah : 168 dan 173.

Almatsier, S. (2001). Prinsip Dasar Ilmu Gizi (pp. 36-38). Gramedia Pustaka Umum.

Aziz, Y. A., \& Chok, N. V. (2013). The Role of Halal Awareness, Halal Certification, and Marketing Components in Determining Halal Purchase Intention Among Non-Muslims in Malaysia: A Structural Equation Modeling Approach. Journal of International Food and Agribusiness Marketing, 25(1), 1-23. https://doi.org/10.1080/08974438.2013.723997

Badan Pusat Statistik Pusat Jakarta. (2010). Statistik Indonesia Tahun 2010. Badan Pusat Statistik Repubublik Indonesia.

Bonne, K., \& Verbeke, W. (2006). Muslim consumer's motivations towards meat consumption in Belgium : qualitative exploratory insights from means-end chain analysis. Anthropology of Food, 5, 0-17. https://doi.org/10.4000/aof.90

Cahyati, R. (2016). Pengaruh Pencantuman Label Halal Terhadap Minat Beli Luwak White Coffe Pada Mahasiswa Fakultas Ekonomi Universitas 17 `Agustus 1945 Samarinda. Ekonomia, 5(3), 94-100.

Fiore, A. M. (2008). The digital consumer: Valuable partner for product development and production. Clothing and Textiles Research Journal, 26(2), 177-190. https://doi.org/10.1177/0887302X07306848

Fung, R. Y. K., Chong, S. P. Y., \& Wang, Y. (2004). A framework of product styling platform approach: Styling as intangible modules. Concurrent Engineering Research and Applications, 12(2), 89-103. https://doi.org/10.1177/1063293X04044381

King, L. (2016). Psikologi Umum (Sebuah Pandangan Apresiatif). Salemba Humanika.

Kotler, P., \& Amstrong, G. (2003). Dasar-Dasar Pemasaran (Edisi ke-9). In J. 1 (Ed.), Dasar-Dasar Pemasaran. PT. Indeks Gramedia.

Kurniawan, P. T. (2017). Hubungan Persepsi Konsumen Tentang Kehalalan Produk Samyang dan Terpaan Persuasi Reference Group Terhadap Minat Beli Produk Samyang. Skripsi.

Nugraha, R., Mawardi, M., \& Bafadhal, A. (2017). Pengaruh Labelisasi Halal Terhadap Minat Beli Konsumen (Survei Pada Mahasiswa Muslim Konsumen Mie Samyang Berlogo Halal Korean Muslim Federation Di Kota Malang). Jurnal Administrasi Bisnis S1 Universitas Brawijaya, 50(5), 113-120.

Rambe, Y., \& Afifuddin, S. (2012). Pengaruh Pencantuman Label Halal pada Kemasan Mie Instan 
terhadap Minat Pembelian Masyarakat Muslim (Studi Kasus pada Mahasiswa Universitas Alwashliyah, Medan). Jurnal Ekonomi Dan Keuangan, 1(1), 14866.

Rao, A. R., \& Monroe, K. B. (1988). The Moderating Effect Of Prior Knowledge On Cue Utilization in Product Evaluations. Journal of Consumer Research, Inc., 4(1), 44. https://doi.org/10.1016/s0098-7913(78)80071-9

Riaz, M. N., \& Chaudry, M. M. (2004). Handbook of Halal Food Production. CRC Press.

Robbins, S. P. (2016). Prinsip-Prinsip Perilaku Organisasi (Edisi ke-5). Erlangga.

Shafie, S., \& Othman, M. N. (2006). Halal Certification: an international marketing issues and challenges. International Marketing and Service, 23(12), 1-11. http://www.ncbi.nlm.nih.gov/pubmed/12568103

Soesilowati, E. S. (2010). Perilaku Konsumsi Muslim dalam Mengkonsumsi Makanan Halal Kasus: Muslim Banten. Seminar Sharia Economics Research Day, 2006, 1-15.

Sumarwan, U. (2011). Perilaku Konsumen (Teori dan Penerapannya Dalam Pemasaran) (p. 46). Penerbit Ghalia Indonesia.

Wahyuni, M. (2015). Persepsi Konsumen Muslim Terhadap Sertifikat Halal (Studi Kasus pada PT. Rocket Chicken Indonesia Cabang Boja Kendal). Skripsi.

Waskito, D. (2015). Pengaruh Sertifikasi Halal, Kesadaran Halal, Dan Bahan Makanan Terhadap Minat Beli Produk Makanan Halal (Sudi Pada Mahasiswa Muslim di Yogyakarta). Universitas Negeri Yogyakarta, 1, 1-12.

Younus, S., Rasheed, F., \& Zia, A. (2015). Identifying the Factors Affecting Customer Purchase Intention. Journal of Management and Business Research: A Administration and Management, Vol. 15(No.2), 1-7. https://doi.org/10.1111/j.1365-2621.1940.tb17194.x 